\title{
Indoor Environmental Quality (IEQ) of Higher Education Institutions (HEIs): A User Perception Survey
}

\author{
M. A. Sulaiman, W. Z. Wan Yusoff, S. Pawi, and W. N. Wan Kamarudin
}

\begin{abstract}
The demand for conducive academic building with healthy environment for teaching and learning (T\&L) activities are rapidly increasing especially in indoor environmental quality (IEQ). Unsatisfactory of IEQ in academic building threaten the quality of $T \& L$ process simultaneously affect the student achievements and teachers performances. This studies are to investigate the IEQ that has been carried out by using survey method and were distributed the questionnaire to the respondent to observe the perception, adaptive behavior and opinion and he questionnaire has been developed based on IEQ elements. The questionnaire was distributed to 370 main user of academic building randomly from 10,000 populations in UTHM It is shown that, the level of user satisfaction is most at the moderate level and some suggestion has been carried out to improve the IEQ in academic building. The collected data has been analyzed by using the Statistical Package for Social Science (SPSS). Several parameters of IEQ elements such as Thermal comfort, acoustic comfort, lighting and Indoor air quality (IAQ) are discussed in this research.
\end{abstract}

Index Terms-Indoor environmental quality, academic buildings, user perception, adaptive behavior.

\section{INTRODUCTION}

Indoor environmental quality (IEQ) is rarely considered as a priority in most development planning and management. IEQ elements cover $21 \%$ of green building evaluation criteria for non-residential building such as academic buildings in higher education intuitions [1]. An imbalance of IEQ can also give negative impact to facilities, building and occupants. This contributes to the health quality of occupant and the case of academic building will affect the teaching and learning process [2]. Besides that, it will contribute for Sick Building Syndrome (SBS), which means a broad definition that includes a variety of symptoms considered to be experienced when the occupants spent time in a particular building. Based on the previous research, a building will be categorized as a sick building when more than $30 \%$ occupants have complained of related symptoms [3]. Based on previous

Manuscript received November 18, 2012; revised January 18, 2013. This work was supported by Office for Research, Innovation, Commercialization and Consultancy (ORICC) University Tun Hussein Onn Malaysia (UTHM) with Grant numbers Vot 1047.

M. A. Sulaiman is with Centre of Excellence for Facilities Management, UTHM, and Malaysia (e-mail: kolonel.azwan@gmail.com).

W. Z. Wan Yusoff is with the Department, Faculty of Technology Management and Business and Deputy Director of Development and Property Management Office UTHM, Malaysia (e-mail: zahari@uthm.edu.my).

S. Pawi is with the Department, Kulai Municipal Council, state of Johor, Malaysia and Member of Malaysia Valuer Associate, Malaysia. (e-mail: Soeb@johor.gov.my)

W. N. Wan Kamarudin is with Chemical Engineering from University Technology Malaysia (UTM).Members of Institution Engineering Malaysia, Malaysia (IEM) (e-mail: wnuraisha@ymail.com) research, normally SBS is closely much related to the building services that include mechanical ventilation relative humidity and fresh air ventilation rates. [4] Normal person spend $90 \%$ the time in the building either in workplace and home, both indoor environmental (IEQ) of home or workplace are equal importance on human health [5]. Most the previous study have focused on the workplace and residential, and not focus in the higher education institutions [4]. IEQ are mainly focus on thermal temperature $\left({ }^{\circ} \mathrm{C}\right)$, relative humidity (\%), acoustic comfort measured in decibel (dB), lighting measured in lux level (lux) and Indoor Air Quality (IAQ), $\left(\mathrm{CO}_{2}\right.$ concentration level and air speed movement) [6]. Objectives of this research are to identify user's perception of IEQ on the academic building. Scope for this study focused in University Tun Hussein Onn Malaysia (UTHM). The campus is located in a mixed development area which includes a long established industrial area. The study is important as it will reflect the quality and health of building occupants which may directly give impact to teaching and learning.

\section{RESEARCH METHODOLOGY}

\section{A. The Study}

The main campus UTHM is located in a mixed development of Parit Raja, Johor. There are industrial park, business center and residential area located adjacent to the main campus i.e. within $1 \mathrm{~km}$ radius. The study focuses on the main academic complex of UTHM namely G3 lecture complex. This is the largest complex for teaching and learning, and is utilized by all faculties of the university.

\section{B. Method of Study}

The questionnaire has been developed based on research objectives to collect/obtain research data. The questionnaire was distributed to 370 main user of academic building randomly from 10,000 populations in UTHM [12]. The data then were analyzed using quantitative methods. A program Statistical Package for Social Science (SPSS) was used in the analysis of the data.

\section{RESUlt AND Discussion}

In order to analyze perception of the IEQ element at UTHM, 370 respondents have been selected to answer the questionnaire from 10, 000 populations in UTHM. 55\% are female while then remaining is male.

\section{A. Demographic}

Based on the Table II, it can be shown 33 respondents or $8.9 \%$ are academic staff's meanwhile 337 respondents or 
$91.1 \%$ are students

TABLE I: SEX OF RESPONDENTS

\begin{tabular}{|c|c|c|}
\hline sex & Frequency & Percent \% \\
\hline Male & 168 & 45 \\
\hline Female & 202 & 55 \\
\hline
\end{tabular}

TABLE II: POSITION OF RESPONDENTS

\begin{tabular}{|l|l|l|}
\hline Position & Frequency & Percent \% \\
\hline Academic Staff & 33 & 8.9 \\
\hline students & 337 & 91.1 \\
\hline Total & 370 & 100 \\
\hline
\end{tabular}

\section{B. Perception on IEQ Elements}

Six points thermal sensation scale in specified in ASHRAE was used to evaluate temperature sensation of occupants [7]. Based on the Table III, on perception of the temperature, 35 respondents $(9.5 \%)$ indicated that the temperature very cold, 135 people (36.5\%) indicated cold, $115(31.1 \%)$ indicated neutral, 60 people $(16.2 \%)$ indicated hot, 18 people $(4.9 \%)$ indicated very hot and 7 people $(1.9 \%)$ indicate not sure. Only small proportion of respondents chooses to indicate their comfort perception in extreme regions.

TABLE III: PERCEPTION OF TEMPERATURE

\begin{tabular}{l|cc}
\hline Perception of temperature & Frequency & Percent $\%$ \\
\hline Very cool & 35 & 9.5 \\
Cold & 135 & 36.5 \\
Neutral & 115 & 31.1 \\
Hot & 60 & 16.2 \\
Very hot & 18 & 4.9 \\
Not sure & 7 & 1.9 \\
Total & 370 & 100 \\
\hline
\end{tabular}

Besides air temperature, relative humidity of the atmosphere is an important parameter determining thermal comfort. Base on Table IV, on perception of relative humidity, a total of $5(1.4 \%)$ of respondent expressed very low, $23(6.2 \%)$ respondents said low, $209(56.4 \%)$ of respondents expressed moderate, 78 respondents o $(21.1 \%)$ said high, $21(5.7 \%)$ of respondents expressed very high and 34 respondents $(9.2 \%)$ said they were not sure. Majority of respondents perceived the humidity level as neutral.

TABLE IV: PERCEPTION OF HUMIDITY

\begin{tabular}{l|ll}
\hline Level of humidity & Frequency & Percent \% \\
\hline Very Low & 5 & 1.4 \\
Low & 23 & 6.2 \\
Neutral & 209 & 56.4 \\
High & 78 & 21.1 \\
Very high & 21 & 5.7 \\
Not sure & 34 & 9.2 \\
Total & 370 & 100 \\
\hline
\end{tabular}

For lighting, previous researchers have developed the model that used lux level to measure visual performance and ways to eliminate visual discomfort resulted from glare [8]. The lighting can change the mood of people and affected their psychology [8]. So, Base on the Table V, the respondents were asked about the perception of light intensity, $11(3 \%)$ of respondent say the intensity of light is very $\operatorname{dim}, 85(23 \%)$ respondents state that $\operatorname{dim}, 166(44.9 \%)$ people expressed neutral, 99 people (26.8\%) said brightly, 7 people $(1.9 \%)$ said very bright and $2(0.5 \%)$ respondent were not sure with the level of light intensity. Overall the respondents indicated their perceptions on light intensity are moderate.

TABLE V: PERCEPTION ON LIGHT INTENSITY

\begin{tabular}{l|cc}
\hline level of lighting & Frequency & Percent \\
\hline Very dim & 11 & 3.0 \\
Dim & 85 & 23.0 \\
Neutral & 166 & 44.9 \\
Bright & 99 & 26.8 \\
Very bright & 7 & 1.9 \\
Not sure & 2 & 0.5 \\
A mount & 370 & 100 \\
\hline
\end{tabular}

Perception of the noise comfort belong to subjective feeling, noise of surrounding get on people's nerve even if the noise does not exceed the standard level. The previous researches placed emphasis on the survey of the invidual's response to noise exposures. The human perception of noise comfort is controlled by both personal and external factor [9],[10]. The normal factors are the human attitude, environmental factor and ability of building to absorb the noise. Respondents invited to evaluate the noise in the academic building at UTHM. Base on the Table VI, result shown the perception of noise comfort, a total of $10(2.7 \%)$ person said it was very noisy, $50(13.5 \%)$ people stated that noise, 276 people (74.6\%) stated neutral, 29 people $(7.8 \%)$ said quietly, one people $(0.3 \%)$ said very quietly and 4 respondent $(1.1 \%)$ said they were not sure.

TABLE VI: PERCEPTION ON NOISE COMFORT

\begin{tabular}{l|cc}
\hline The sound level & Frequency & Percent \\
\hline Very noisy & 10 & 2.7 \\
Noise & 50 & 13.5 \\
Neutral & 276 & 74.6 \\
Silent & 29 & 7.8 \\
Very quiet & 1 & 0.3 \\
Not sure & 4 & 1.1 \\
Total & 370 & 100 \\
\hline
\end{tabular}

TABLE VII: PERCEPTION OF INDOOR AIR QUALITY (IAQ)

\begin{tabular}{l|cc}
\hline Level of ventilation & Frequency & Percent \\
\hline Very good & 7 & 1.9 \\
Good & 94 & 25.4 \\
Neutral & 177 & 47.8 \\
Bad & 80 & 21.6 \\
Very bad & 9 & 2.4 \\
Not sure & 3 & 0.8 \\
Total & 370 & 100 \\
\hline
\end{tabular}

In the case study, UTHM are located in the mix development, almost the building are close to the main roads and industrial park. The contaminants are easily transferred into the building especially class room. Fumes emitted from vehicle and industry undertakings are trapped in the building. Respondents asked to indicate their perception about IAQ level in the building. Base on the Table VII, on Perception of indoor air quality (IAQ), 6 people $(1.6 \%)$ mentioned very good, 63 people (17\%) said good, 153 people $(41.4 \%)$ said 
neutral, 115 respondent (31.1\%) stated poor, 29 people (7.8\%) said very poor and 4 people $(1.1 \%)$ were not sure.

\section{Adaptive Behavior}

Adaptive behavior is a human instinct to adopt changes when they are experiencing discomfort hence people can still accommodate in the building [6]. Fig. 1 shows the percentage adaptive behavior to low temperature. Of the 370 respondents, $47 \%$, or 175 people said they imposed sweaters, $48 \%$ or 178 people said they increase the temperature of air conditioning, and a total of $5 \%$ or 17 people expressed a variety of ways. Almost the respondents indicate to increase the air conditioning temperature and wearing the sweater in the building.
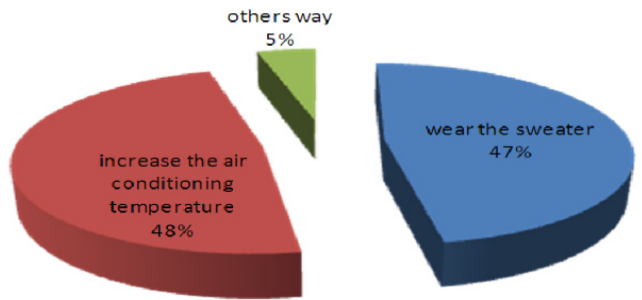

Fig. 1. Percentage adaptive from low temperature

Sometimes, the temperature in the class room will be increasing when there are many factors influenced the temperature increasing such as the air conditioning fail to function, the class are very crowded and the ventilation failed. But, the users need to adapt the situation because the Teaching and learning process (T\&L) still need to run. Fig. 2 shows that the percentage adaptive behavior to high temperatures. $44 \%$ or 161 people said they decrease the temperature of air-conditioning, $36 \%$ or 134 people mentioned they open the door, $16 \%$ or 59 people said they do not wear clothes that trap heat and $4 \%$ or 16 people stated other means.

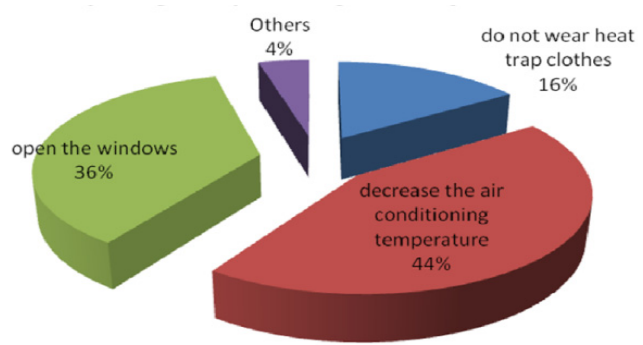

Fig. 2. Percentage adaptive from high temperature

The outdoor and indoor lighting are very important because it influence the people's mode [6]. In this survey, the respondent asked how they would adapt the intensity of lighting either when it bright and dim in lighting.

Fig. 3 shows the adaptive behavior to bright lighting. From 370 respondents, $55 \%$ or 203 people said they did not close the curtains to let light in, $38 \%$ or 142 people said they decreased the number of lights and $7 \%$, or 25 persons indicate otherwise. Meanwhile, Fig. 4 shows the percentage adaptive behavior to the dim lighting. $5 \%$ or 188 people said they increase the number of lights, $46 \%$ or 172 people stated that they allowed day light to enter into the building and $3 \%$, or 10 persons indicated otherwise.

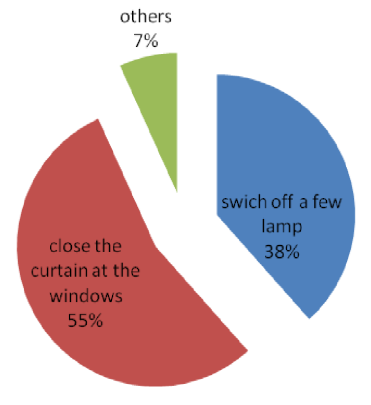

Fig. 3. Adaptive from bright lighting

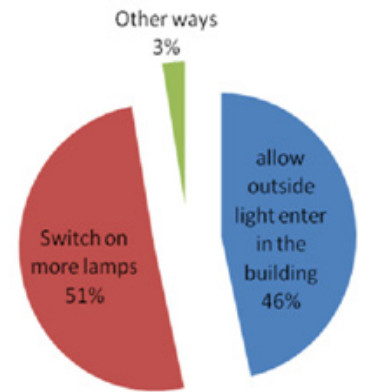

Fig. 4. Adaptive from dim lighting
Noise is one of the disturbances in T\&L especially when the noises come from the outside. It makes users susceptible to concentrate to T\&L activities running as well. However, that poor condition can reduced which the user have mitigation strategy to adapt the noise disturbance. Fig. 5 shows the adaptive behavior to the noises from outside. 309 or $83.5 \%$ respondents stated that they close the window properly to prevent the outside noise into the building. Meanwhile, 38 or $3.1 \%$ respondents stated that they report to authorities and 23 or $6.2 \%$ have variation opinion.

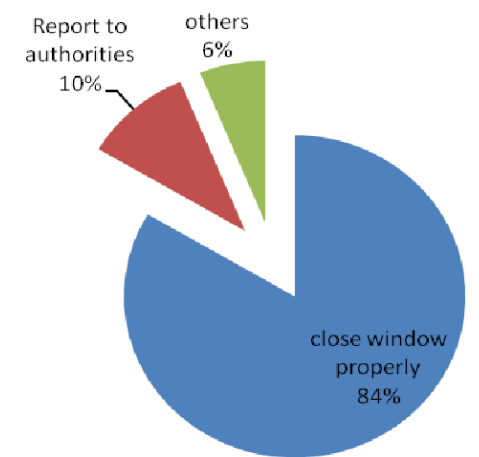

Fig. 5. Percentage adaptive from noises from outside

Air quality gives high impact to user's health. The appearance of contaminant of dust level, $\mathrm{CO}_{2}, \mathrm{CO}$ concentration and others respirable particles may cause long term effect to user. It is important to user to adapt and prevent it. Fig. 6 shows about the adaptive behavior of the unfavorable IAQ. $90 \%$ or 332 people were masks, 7 or $27 \%$ justified the fresh air from the outside in. and $3 \%$ expressed by various means.

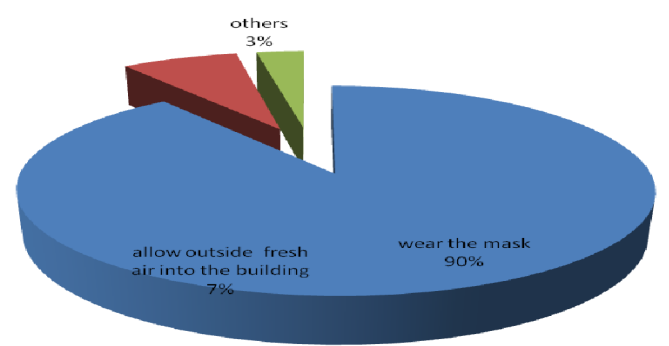

Fig. 6. Percentage adaptive from unfavorable IAQ

\section{Opinion and Suggestion of Respondent}

Respondents were asked about their overall opinion for IEQ. It is as the indicator for facility management on how far the IEQ level in the building based on user perceptions. Table VIII shows the respondents' view on the overall IEQ level of academic buildings in UTHM. Out of 370 total respondents, 9 respondents or $2.4 \%$ said very good, 77 people or $20.8 \%$ 
said good, 166 people or $44.9 \%$ stated moderate, 88 people or $23.8 \%$ said not good, 30 people or $8.1 \%$ stated very good.

TABLE VIII: PERCEPTION OF OVERALL IEQ

\begin{tabular}{l|cc}
\hline IEQ level & Frequency & Percent $\%$ \\
\hline Very Good & 9 & 2.4 \\
Good & 77 & 20.8 \\
Moderate & 166 & 44.8 \\
Not good & 88 & 23.8 \\
Very not good & 30 & 8.1 \\
Not Sure & 0 & 0.0 \\
Total & 370 & 100 \\
\hline
\end{tabular}

Teaching and Learning (T\&L) sure effected when the IEQ level are under prescribed. Table IX shows the respondents' opinion on the effect of IEQ to the teaching and learning process. On this part, 330 or $89 \%$ of total 370 respondents said Yes, 29 or $8 \%$ respondents indicated no effect and a total of 11 or $3 \%$ respondent said they were not sure.

TABLE IX: OPINION IEQ EFFECT TO T\&L PROCESS

\begin{tabular}{l|cc}
\hline Opinion & Frequency & Percent \% \\
\hline Yes & 330 & 89.2 \\
No & 29 & 7.8 \\
Not Sure & 11 & 3.0 \\
Total & 370 & 100 \\
\hline
\end{tabular}

Table X shows the opinion of respondents on the influence of IEQ to the health impact. For this question, 292 (79\%) persons indicate yes, 49 (13\%) people express no and $30(8 \%)$ people express uncertain.

\begin{tabular}{l|cc}
\multicolumn{3}{c}{ TABLE X: OPINION IEQ EFFECT THE HEALTH } \\
\hline Opinion & Frequency & Percent \% \\
\hline Yes & 292 & 78.9 \\
No & 48 & 13.0 \\
Not sure & 30 & 8.1 \\
Total & 370 & 100 \\
\hline
\end{tabular}

TABLE XI: SUGGESTION THE IMPROVE IEQ

\begin{tabular}{l|cc}
\hline Opinion & Frequency & Percent \% \\
\hline Maintenances & 124 & 33.5 \\
Green Technology & 48 & 13.0 \\
Control the behavior & 25 & 6.8 \\
Close the industrial park & 107 & 28.9 \\
Upgrade the class layout & 31 & 8.4 \\
No opinion & 35 & 9.5 \\
total & 370 & 100 \\
\hline
\end{tabular}

Table XI shows the respondents' suggestion to improve IEQ in academic building. 124 respondents or $33.5 \%$ suggested on improving maintenance. 48 respondents or $13 \%$ suggested on authority for adopting green technology. 25 or $6.8 \%$ said the user should control the behavior in the building 107 or $28.9 \%$ respondents suggest to relocate the industrial park currently located adjacent to UTHM. 31 or $8.4 \%$ said the class arrangement to be upgraded and the remaining, 31 respondents no suggestion. The suggestion from respondent is very important to facility management to improve the IEQ in building to make the user more comfortable and conducive. It is because, although the facility management already made the maintained or improvement, it did not give the satisfaction to the users, because maybe there are some errors occurred when the process is running.

\section{CONCLUSION}

Further to this research, it can be shown that the level of satisfaction for the majority of user at the academic building in UTHM is at moderate level. A few actions should be taken into consideration to produce a good IEQ environment at the academic building in UTHM. Most of the correspondences suggest improving on maintenance of the building. Poor maintenance will affect the building's environment quality and it highly influences productivity and well being of the facility management. They should give priority on the maintenances aspect as this will affect the core business of university. Other suggestions are to close industrial park, improve class layout and implement the green technology. The result shows that the user responses provide useful indicators of suggestion. The studies provide a useful suggestion based on responses for facility management to take decision to improve it. Facility management is responsible in providing an atmosphere in which conducive environmental in the buildings should take into account of the views and suggestions from users. IEQ give big effects on consumers as well as the main uses, and facility management should never take this case for granted.

\section{REFERENCES}

[1] GBI organization. [Online]. Available: www.greenbuildingindex.com 2009.

[2] S. A. Alsagoff, "Sociology in Education," first edition, 1985, pp. 19.

[3] M. Y. M. Zainal, "Getting to Know Our Buildings Better: Ventilation, Thermal Comfort," Air Freshness, Indoor Air Quality (IAQ), Sick Building Syndrome (SBS) UTHM, 2011

[4] S. Muhic and Butala, "The influence of indoor environment in the office building on their occupant: expected-unexpected," Building \& Environment, vol. 39, pp. 289-96, 2004.

[5] N. H. Wong and B. Huang, "Comparative study of the indoor air quality of naturally ventilated and air-conditioned bedrooms of residential building in Singapore," Building \& Environment, vol. 37, pp. 1267-1277, 2004.

[6] E. H. W. Chan, K. S. Lam, and W. S. Wong, Evaluation on indoor environment quality of dense urban residential buildings.

[7] A. Stad, Thermal Environmental Condition for human Occupancy, vol. $55,2004$.

[8] B. PR, "Lighting research for interiors the beginning of the end or end of beginning," lighting Research and Technology, vol. 36, no. 4, pp. 283-294, 2004.

[9] M. A. Wallenies, "The interaction of noise stress and personal project stress on subjective health," Journal Environmental Psychology, vol. 24, pp. 167-177, 2004.

[10] H. M. E Miedema and H. Vos, "Demograhic and attitudinal factors that modify annoyance from transportation noise," Journal Society of America, vol. 105, no. 6, pp. 3336-3344, 2004.

[11] K. Morgan, "Determining Sample Size For Research Activities," Educational And Psychological Measurement, 1970, vol. 30, pp. 607-610.

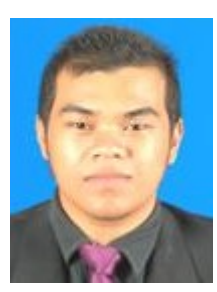

Muhammad Azwan Sulaiman was born in Kota Bharu, Kelantan and grows up in Besut, Terengganu, Malaysia. Got the early education at Padang Luas Primary School, and continue the study at MARA Junior Science Collage for secondary level. After pass the foundation studies at Pahang Matriculation Collage, he continued study for bachelor degree in Real Estate Management at University Tun Hussien Onn Malaysia (UTHM) and was finished by early 2012. Currently, he is one of the Centre of Excellent of Facilities Management members at UTHM. 